Supplementary material for Preminger JE, et al, 2015. Adult-children's perspectives on a parent's hearing impairment and its impact on their relationship and communication, Int J Audiol, 54, 720-726.

\section{Appendix Interview guide}

This is a guide to the topics that should be covered in the interview. These particular questions don't need to be asked, nor do they need to be asked in this order. Let the interview be as open as possible, but at the end, make sure that each area is discussed.

\section{First noticing the hearing loss}

- When did you begin to think or notice that your parent had a problem with hearing?

- Can you describe a situation (or situations) during which you became aware that something was wrong with your parent's hearing?

- What did you do or say when you first noticed your parent's hearing loss?

\section{Seeking rehabilitation for hearing loss}

- Who decided that your parent should seek help for his/her hearing loss? Did you have a role in this decision? What was it?

- What was your role in your parent's hearing help seeking? Did you accompany your parent to clinic visits? Did you discuss the visits with your parent?

- What was this experience like for you?

- What is your role with your parent as a hearing aid user? Do you have to help with it? Do you have to remind your parent to wear it?
- How is the situation now?

- What has been the greatest challenge in dealing with ... (your parent's hearing loss, your parent's hearing aid)?

\section{The social and relational implication of the hearing loss}

- How has your parent's hearing loss affected you and your everyday life? (What has changed since before hearing loss, can you give an example?)

- How has your parent's hearing loss affected your relationship with your parent? (Do you see each other more or less often, have you taken on new roles as a result?)

- How has your parent's hearing loss affected your communication with your parent? (Has your communication changed? Has what you talk about changed?)

- Are there things you and your parent no longer talk about (as a result of hearing loss)?

- What communication strategies do you use in order to communicate effectively with your parent? (Is it possible to converse the way that you used to?)

- Have you talked with your parent about how to communicate? About how to improve communication?

- Do you think the hearing loss has affected your life, and your relationship with your parent, in a positive way? (examples?) 